\title{
The Social, Cultural, Philosophical, and Ideological Basis of Education with The Style of Marhaenism
}

\section{ALIM HARUN PAMUNGKAS}

Lecturer of Department of Nonformal Education

Faculty of Education, Padang State of University Email: pamungkasd527@gmail.com

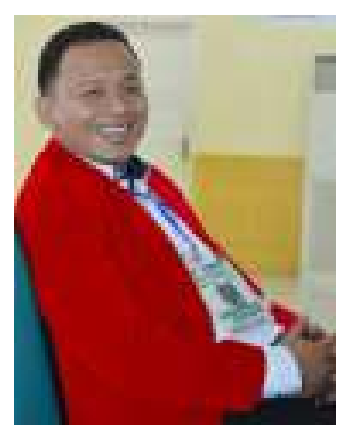




\section{COMMUNITY}

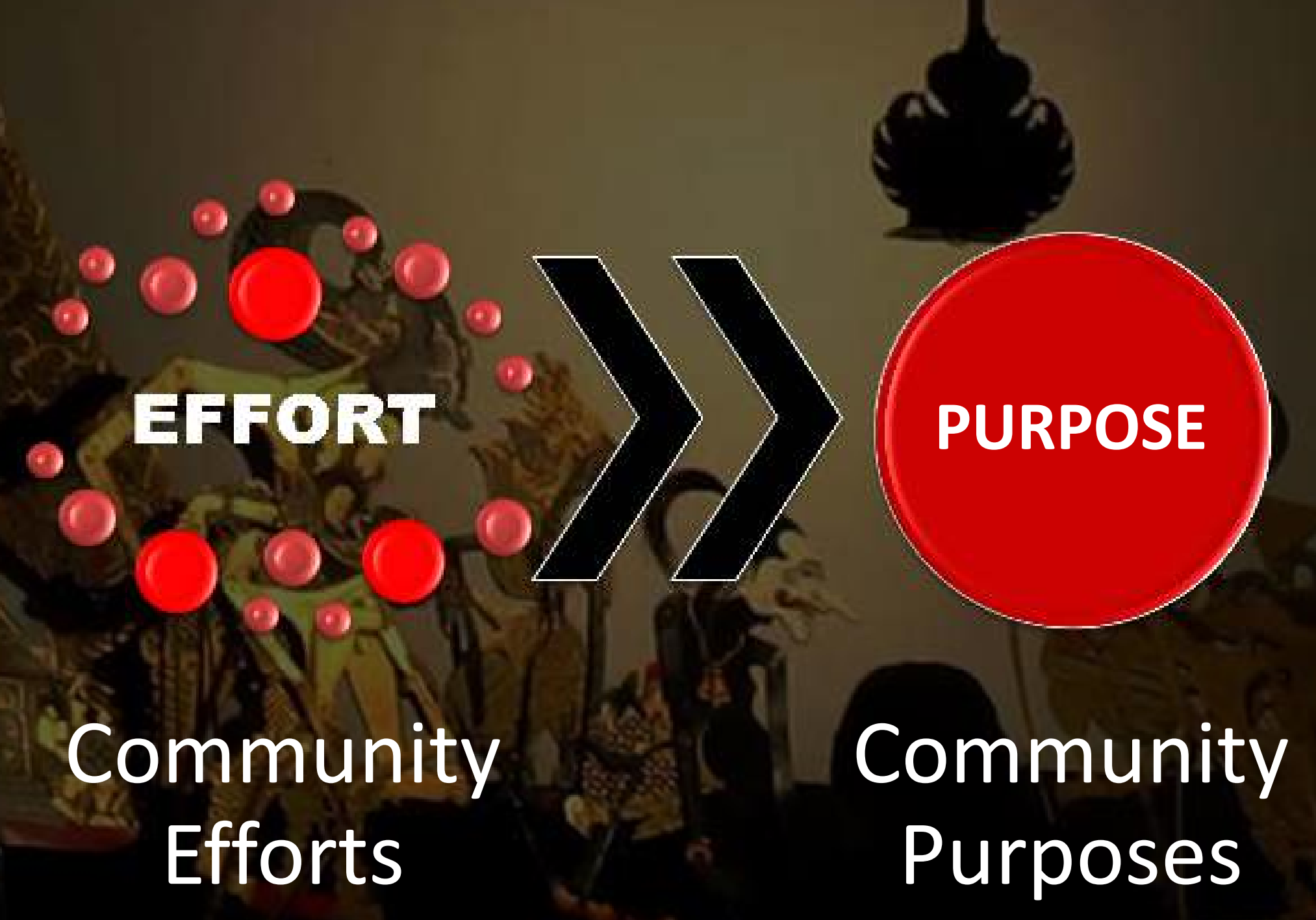




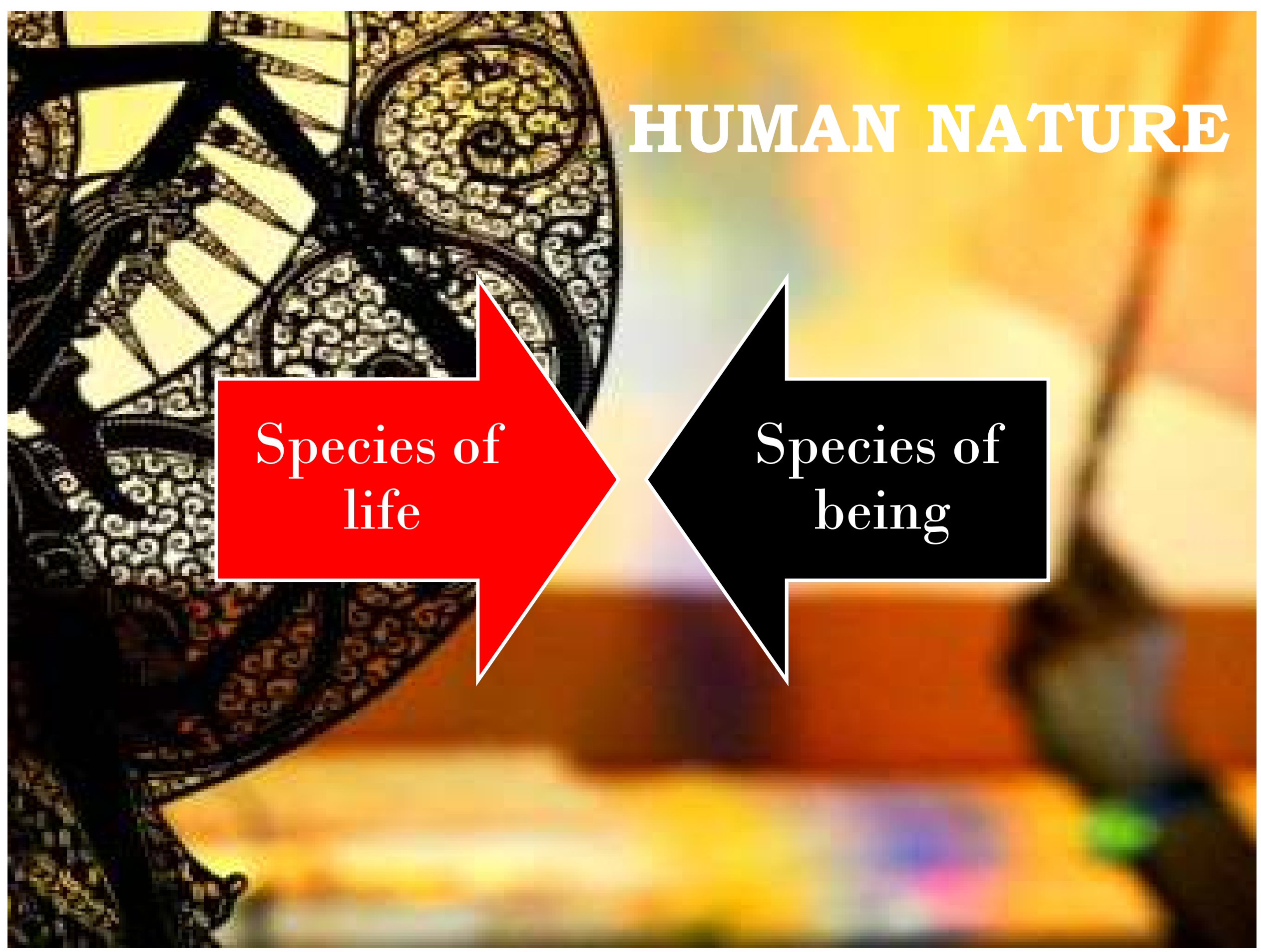




\section{LEARNING AS A PROCESS}

Production -

Reproduction

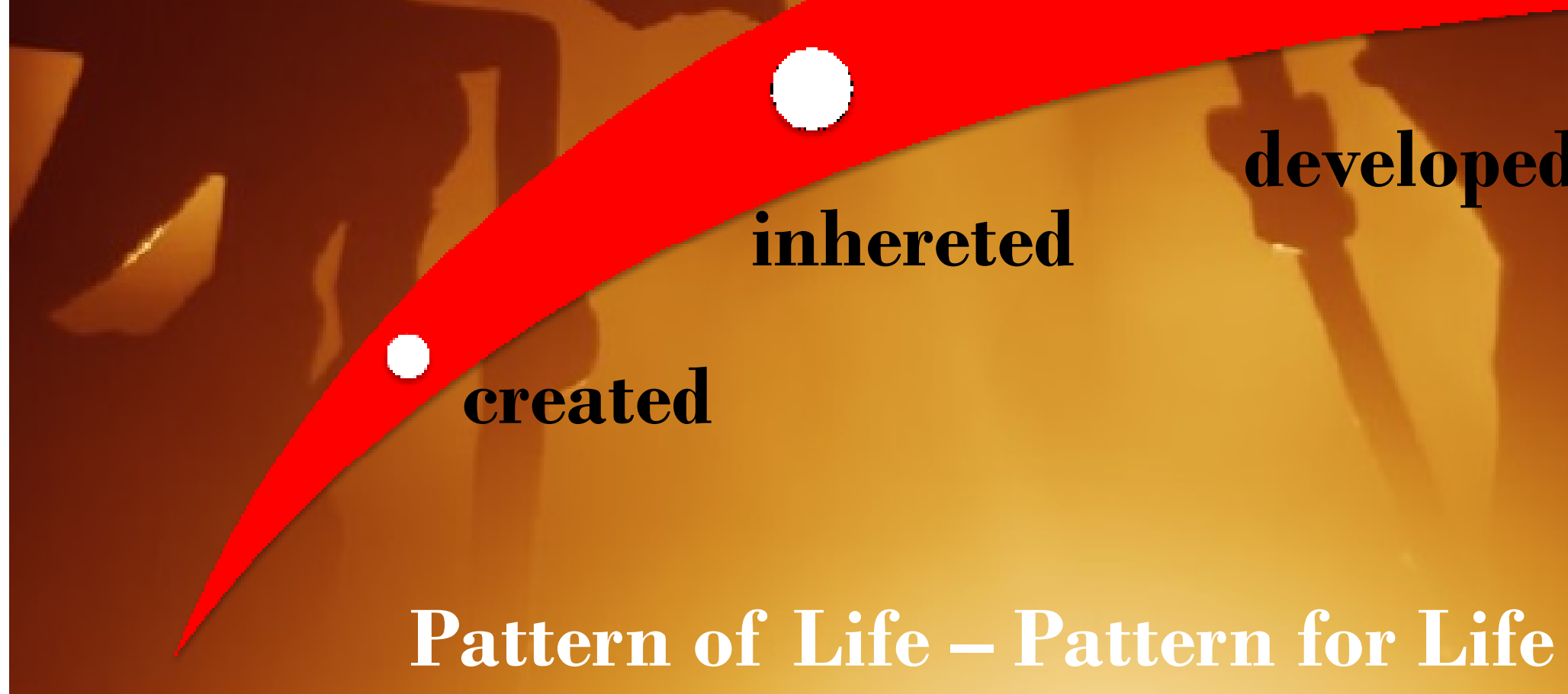




\section{UNIVERSAL \\ IDEALS}
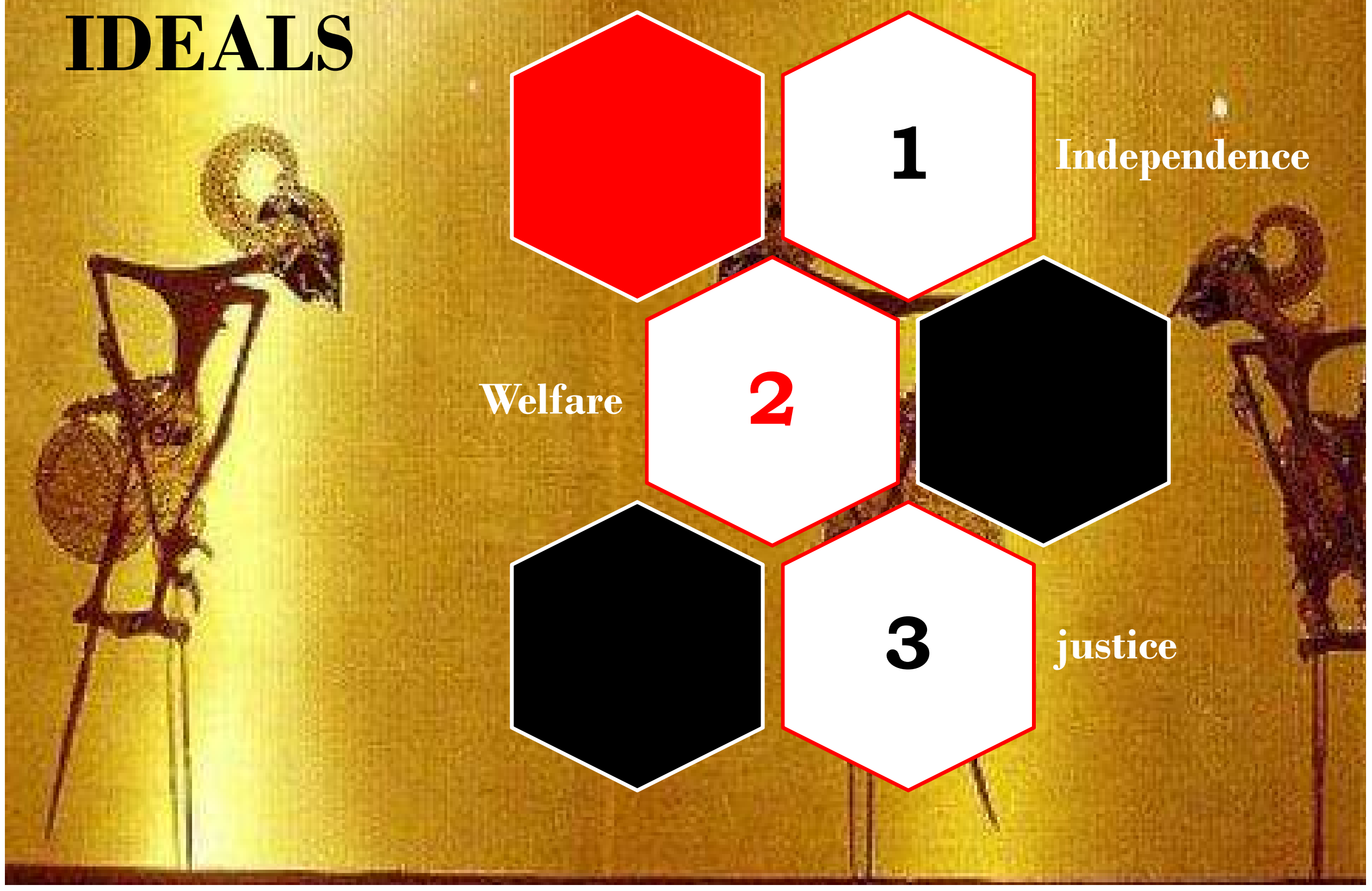


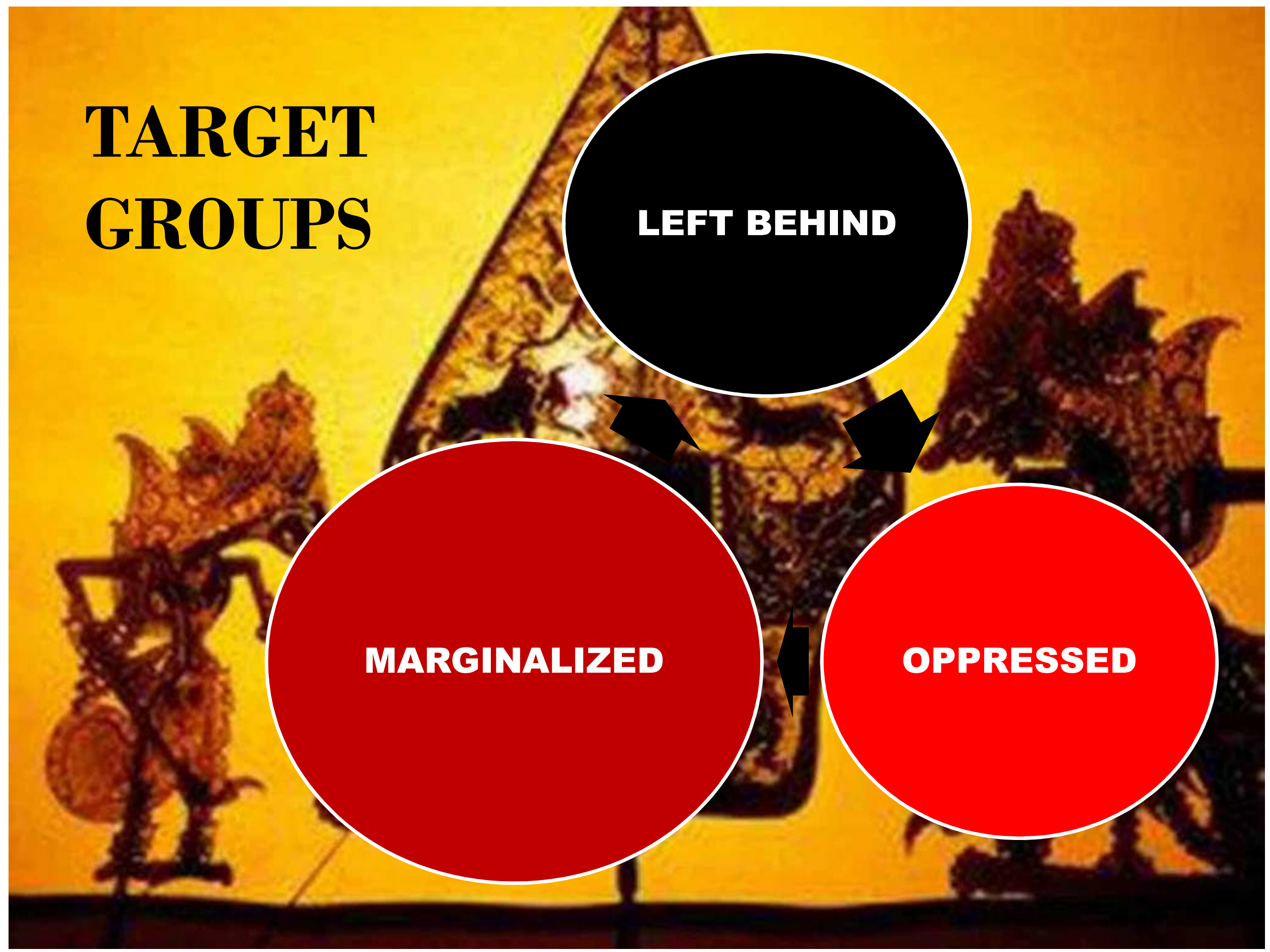




\section{WORKING TO}

INDONESIA THROUGH EDUCATION

public policy

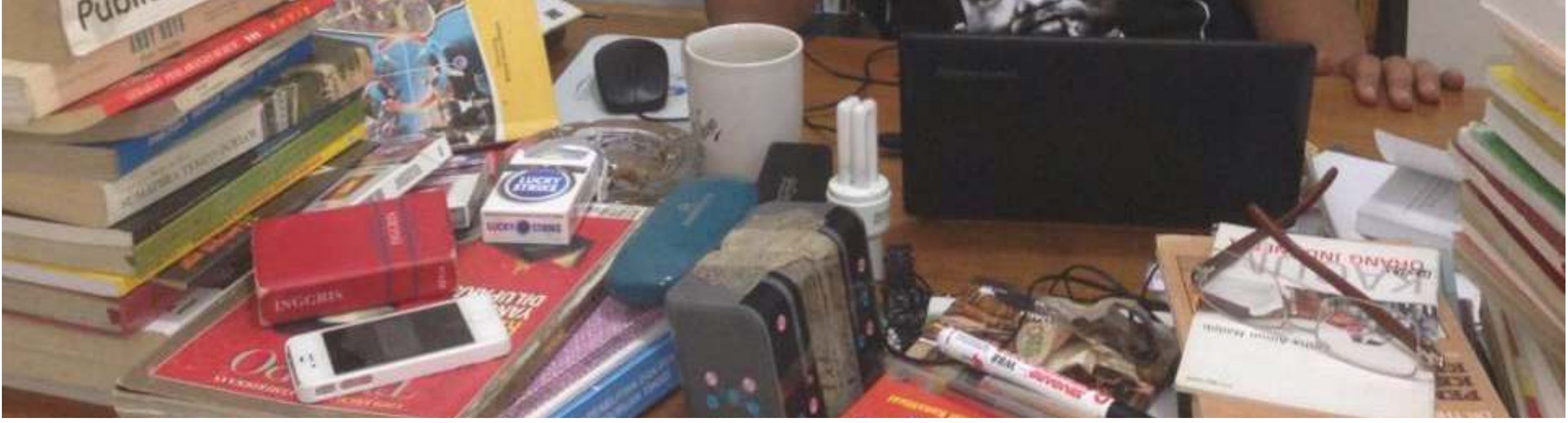

